\title{
Slecht nieuws communiceren in de diergeneeskunde: wat is de goede aanpak?
}

\author{
Breaking bad news in veterinary medicine: what is the best approach?
}

\author{
A. Decloedt \\ Vakgroep Inwendige Ziekten van de Grote Huisdieren, \\ Faculteit Diergeneeskunde, Universiteit Gent, \\ Salisburylaan 133, 9820 Merelbeke, België
}

Annelies.Decloedt@Ugent.be

\section{AMENVATTING}

Slecht nieuws kan gedefinieerd worden als elke boodschap met een nadelige invloed op het toekomstbeeld van de klant. Slechtnieuwsgesprekken komen frequent voor in de diergeneeskunde en de dierenarts-klantrelatie wordt in belangrijke mate bepaald door de manier waarop het slechte nieuws gecommuniceerd wordt. In de humane geneeskunde en meer recent ook in de diergeneeskunde bestaan verschillende richtlijnen om een slechtnieuwsgesprek uit te voeren met minder stress en meer voldoening bij zowel dierenarts als klant. In de uiteenlopende modellen kunnen vijf essentiële elementen gevonden worden. Als eerste is er de voorbereiding van het gesprek, met het creëren van een juiste setting. Vervolgens wordt het perspectief van de klant bevraagd, gevolgd door het kort en direct meedelen van het slechte nieuws zelf en het empathisch reageren op eventuele emoties. Verdere informatie en een planning volgen in kleine hoeveelheden op het moment dat de klant hier terug voor open staat.

\section{ABSTRACT}

Bad news can be defined as any news which negatively affects the client's future perspective. Bad news conversations are frequent in veterinary medicine, and the way these are conducted has a major impact on the veterinarian-client relationship. In human medicine, and more recently also in veterinary medicine, several strategies have been formulated for delivering bad news in order to reduce stress and enhance satisfaction for both the veterinarian and the client. Five essential elements can be found in the different models for these challenging interactions. First, the conversation should be prepared ahead if possible, and an appropriate setting for the conversation should be created. Next, the client's perspective about his animal's disease is explored, followed by the bad news message itself in short, understandable pieces, while responding empathically to emotions, which may arise. Further information and planning is then provided in small chunks when the client is ready for this.

\section{INLEIDING}

Communiceren met klanten is een van de meest gebruikte vaardigheden binnen de diergeneeskundige praktijk. Naar analogie met de humane geneeskunde voert een dierenarts naar schatting 120.000-160.000 gesprekken met klanten gedurende zijn of haar loopbaan (Frankel, 2006). Een aanzienlijk deel van deze conversaties bestaat uit het brengen van slecht nieuws (Nickels en Feeley, 2018; Ptacek et al., 2004). Slecht nieuws wordt in de medische wereld gedefinieerd als "elk nieuws dat de kijk van de patiënt op zijn/haar toekomst ernstig en nadelig beïnvloedt" (Buckman, 1984). Een bredere, meer omvattende definitie van een slechtnieuwsgesprek is "elke situatie die een gevoel van wanhoop opwekt, een bedreiging van het mentale of fysieke welzijn van de patiënt inhoudt, waarbij er kans is dat de gebruikelijke levensstijl verstoord wordt of waarin een boodschap gegeven wordt die leidt tot een beperking van de keuzes in het leven van de patiënt" (Rosenbaum et al., 2004). Onder slecht nieuws in de diergeneeskunde valt met andere woorden elke boodschap die in de ogen van de klant ernstig en negatief is, zelfs als deze informatie dat 
niet is in de perceptie van de dierenarts. Het meest duidelijke voorbeeld van slecht nieuws is uiteraard de boodschap dat euthanasie moet overwogen worden of de enige optie is. Voor de klant kan het echter ook slecht nieuws zijn dat de merrie of koe niet drachtig is, dat de hond artrose heeft of dat de kat chronische nierproblemen heeft. Slecht nieuws komt dus zeer frequent voor in de dagelijkse praktijk, zowel bij gezelschapsdieren als productiedieren (Ptacek et al., 2004; Shaw en Lagoni, 2007). Het is niet altijd makkelijk in te schatten welke boodschappen voor de klant "slecht nieuws" zijn. Bij slepende, onverklaarbare klachten kan de klant bijvoorbeeld duidelijkheid verkiezen boven onzekerheid over de diagnose of prognose. In die zin kan het zelfs een opluchting zijn om te horen welke ernstige ziekte het dier heeft. Daartegenover kan het dan weer als slecht nieuws ervaren worden om te horen dat er geen afwijkingen gevonden zijn bij een onderzoek, waardoor er dus nog geen verklaring is voor de symptomen van het dier.

De mededeling van slecht nieuws staat zelden op zichzelf. Vaak volgt na een eerste mededeling van slecht nieuws een proces van rouw. Daarnaast wordt een eerste slechtnieuwsgesprek vaak gevolgd door vervolgconsultaties. Na de diagnose van een ernstige ziekte wordt het dier bijvoorbeeld verder opgevolgd en moet uiteindelijk misschien zelfs de beslissing tot euthanasie genomen worden. Tijdens deze vervolggesprekken kan de klant anders reageren op verder slecht nieuws dan tijdens het initiële gesprek. Het is ook mogelijk dat de klant nog volledig van mening verandert of later komt met nieuwe vragen. De vervolgconsultaties na het eerste slechtnieuwsgesprek worden dus het beste op dezelfde manier aangepakt als het eerste gesprek, met aandacht voor de emoties en zorgen van de klant. De emoties die opgeroepen worden door slecht nieuws verschillen sterk naargelang de persoon en de situatie (Shaw en Lagoni, 2007). Een identieke situatie kan bij verschillende individuen een totaal verschillende reactie uitlokken. Daarnaast kunnen ook bij dezelfde persoon verschillende emoties opgeroepen worden door slecht nieuws, bijvoorbeeld verdriet, woede, opluchting of zelfs ogenschijnlijke onverschilligheid. Het is belangrijk om deze emoties te accepteren zonder te oordelen, zeker indien de emoties verschillen van de verwachtingen van de dierenarts.

Het goed communiceren van slecht nieuws is van groot belang voor de relatie tussen dierenarts en klant en de tevredenheid van zowel klant als dierenarts, zeker tijdens gesprekken over de moeilijkste onderwerpen, zoals ernstige ziekte of euthanasie (Buckman, 1992; Rosenbaum et al., 2004; Shaw en Lagoni, 2007). Een slechtnieuwsgesprek is vaak een sleutelmoment dat de band tussen dierenarts en klant kan maken of kraken. Indien het slechte nieuws niet correct gecommuniceerd wordt, kan dit aanleiding geven tot ontevredenheid over de dierenarts, een moeilijker rouwproces voor de klant en een hogere kans op klachten achteraf (Roberts et al., 1994; Shaw en Lagoni, 2007).
Voor de dierenarts zelf en de andere leden van het praktijkteam gaat het brengen van slecht nieuws ook vaak gepaard met stress voor, tijdens of in mindere mate na het gesprek (Ptacek et al., 2004; Williams en Mills, 2000). In de humane geneeskunde blijkt uit onderzoek dat naast ervaring ook training van artsen in het brengen van slecht nieuws ervoor zorgt dat ze hier beter mee kunnen omgaan (Fallowfield en Jenkins, 2004). Artsen die gebruik maken van een protocol voor een slechtnieuwsgesprek, ervaren minder angst en stress bij het brengen van slecht nieuws (Baile et al., 2000). Ook in de diergeneeskunde bestaat goede dierenarts-klantcommunicatie uit verschillende vaardigheden die aangeleerd kunnen worden (Adams en Kurtz, 2017). Training in het communiceren van slecht nieuws, zeker voor studenten of dierenartsen met relatief weinig ervaring, kan potentieel zorgen voor een grotere professionele tevredenheid en een afname van 'compassion fatigue' en zelfs burn-out (Buckman, 1992; Ptacek et al., 2004).

\section{RICHTLIJNEN VOOR HET SLECHTNIEUWS- GESPREK}

Voor de aanpak van slecht nieuws zijn verschillende modellen beschreven in de humane geneeskunde en diergeneeskunde. Een overzicht wordt gegeven in Figuur 1. Het meest gebruikte protocol is het 'SPIKES'-model (Buckman, 1992). Dit model werd initieel ontwikkeld binnen de humane oncologie voor het meedelen van slecht nieuws aan patiënten met kanker (Baile et al., 2000). Het model werd ook beschreven voor het aanleren van het slechtnieuwsgesprek in de diergeneeskunde, met name met betrekking tot euthanasie (Hewson, 2015; Shaw en Lagoni, 2007). Het SPIKES-model bestaat uit zes stappen: het creëren van de juiste omstandigheden voor het gesprek (Setting), het nagaan hoe de patiënt/klant de situatie zelf inschat (Perspective) gevolgd door het vragen van toestemming om het slechte nieuws mee te delen (Invitation), het geven van informatie (Knowledge), het omgaan met de opgewekte emoties (Emotions/Empathic Response) en tot slot het bespreken en samenvatten van een plan voor de toekomst (Strategy/Summarize). Een ander chronologisch protocol voor het stapsgewijs meedelen van slecht nieuws in de humane geneeskunde is het ABCDEmodel (Rabow en McPhee, 1999; Vandekieft, 2001). Dit model start met de voorbereiding van het gesprek (Advance preparation), vervolgens de opbouw van een vertrouwensrelatie met de patiënt (Build therapeutic relationship), om daarna duidelijk en helder de boodschap te communiceren (Communicate well), de reacties van de patiënt actief te beluisteren (Deal with reactions) en tot slot de emoties en verdere noden van de patiënt aan te kaarten en hem indien nodig verder door te verwijzen (Encourage/validate emotions). Een adaptatie van dit model werd reeds voorgesteld voor gebruik in de veterinaire oncologie (Vala et al., 


\begin{tabular}{|c|c|c|c|}
\hline SPIKES & ABCDE & CLEMENS & COMFORT \\
\hline $\begin{array}{c}\text { Setting } \\
\text { Perspective } \\
\text { Invitation } \\
\text { Knowledge } \\
\text { Emotions/ } \\
\text { Empathic response } \\
\text { Strategy/ } \\
\text { Summarize }\end{array}$ & $\begin{array}{l}\text { Advance } \\
\text { preparation } \\
\text { Build therapeutic } \\
\text { relationship } \\
\text { Communicate well } \\
\text { Deal with } \\
\text { Reactions } \\
\text { Encourage/ } \\
\text { validate emotions }\end{array}$ & $\begin{array}{l}\text { Context } \\
\text { Luisteren } \\
\text { Evalueren } \\
\text { Meedelen } \\
\text { Emoties } \\
\text { Nazorg } \\
\text { Strategie }\end{array}$ & $\begin{array}{c}\text { Communication } \\
\text { Orientation/ } \\
\text { Opportunity } \\
\text { Mindful } \\
\text { communication } \\
\text { Family } \\
\text { Opening } \\
\text { Relating } \\
\text { Team }\end{array}$ \\
\hline
\end{tabular}

Figuur 1. Overzicht van de verschillende modellen beschreven in de humane geneeskunde en diergeneeskunde voor het brengen van slecht nieuws.

2016). Als Nederlandstalige richtlijn voor artsen werd het CLEMENS-protocol ontwikkeld (De Lepeleire en Keirse, 2011). "Clemens" betekent zachtmoedig, en staat als acronym voor: de Context van het gesprek voorbereiden, Luisteren (vooraleer zelf te spreken), Evalueren en inschatten van de gewenste informatie en emoties bij de patiënt, Meedelen van het slechte nieuws, Emoties laten ventileren, Nazorg bieden door onder meer actief te luisteren en gevoelens te erkennen en tot slot de situatie samenvatten en de verdere Strategie bespreken.

Meer recent werd het COMFORT-model voorgesteld dat verschillende basisprincipes voor het brengen van slecht nieuws omvat zonder vaste volgorde van deze elementen. Dit model werd uitgewerkt voor communicatie in een palliatieve setting in de humane geneeskunde (Villagran et al., 2010; Wittenberg et al., 2018). De elementen van dit model zijn: een goede dialoog tussen arts en patiënt (Communication), het overlopen van de verschillende diagnostische en therapeutische opties en hun prognose (Orientation and Opportunity), het aandacht geven van de arts aan de patiënt en zijn/haar zorgen (Mindful communication), de aanwezigheid van familie van de patiënt (Family), het identificeren van wat voor de patiënt en zijn/haar familie het belangrijkste is (Opening), rekening houden met het perspectief van de patiënt en zijn/haar familie en indien nodig de boodschap verschillende

Tabel 1. Schematisch overzicht en voorbeeld van de algemene aanpak van een slechtnieuwsgesprek in de diergeneeskunde.

\begin{tabular}{|c|c|}
\hline & Aanpak van slecht nieuws: vijf elementen \\
\hline Voorbereiding & $\begin{array}{l}\text { - Voldoende tijd } \\
\text { - Rustige ruimte } \\
\text { - Klant en eventueel familieleden aanwezig } \\
\text { - Dierenarts inhoudelijk voorbereid (kent alle gegevens) }\end{array}$ \\
\hline Eigenaarsperspectief bevragen & $\begin{array}{l}\text { "Voor we de resultaten bespreken, zou ik er graag zeker van zijn dat we op } \\
\text { dezelfde golflengte zitten. Kan u mij eens vertellen wat u op dit ogenblik weet } \\
\text { over de ziekte van Toby?" } \\
\text { "Sommige mensen willen graag alle informatie en anderen verkiezen enkel } \\
\text { de belangrijkste zaken. Wat wilt u liefst?" }\end{array}$ \\
\hline Slecht nieuws meedelen & $\begin{array}{l}\text { - Eerst "warning shot': "Het spijt mij, ik heb slecht nieuws" } \\
\text { - Vervolgens boodschap zo kort mogelijk, eerlijk, direct. }\end{array}$ \\
\hline $\begin{array}{l}\text { Emotionele reacties / } \\
\text { Empathisch reageren }\end{array}$ & $\begin{array}{l}\text { "Ik merk dat dit heel moeilijk is voor u. Ik hoor dat u kwaad bent, dat is } \\
\text { volledig normaal. Ik zou ook kwaad zijn als mij dit zou overkomen. } \\
\text { Ik begrijp dat u moeilijk kan geloven dat dit gebeurd is, } \\
\text { het is allemaal heel snel gegaan." }\end{array}$ \\
\hline Plannen & $\begin{array}{l}\text { - Kleine hoeveelheden informatie } \\
\text { - Regelmatig bevragen klant, herhalen, samenvatten } \\
\text { - Eventueel hulpmiddelen gebruiken vb. noteren }\end{array}$ \\
\hline
\end{tabular}


keren herhalen (Relating) en tot slot het belang van efficiënte samenwerking binnen het hele medische team (Team). Uit een bevraging bij 44 dierenartsen bleek dit model ook nauw aan te sluiten bij de meest gebruikte strategieën voor het brengen van slecht nieuws in de gezelschapsdierenpraktijk (Nickels en Feeley, 2018).

\section{AANPAK SLECHTNIEUWSGESPREK}

De rode draad doorheen de verschillende modellen voor het slechtnieuwsgesprek zijn vijf stappen (Tabel 1): (1) de voorbereiding, (2) het navragen van het eigenaarsperspectief, (3) het brengen van het slechte nieuws zelf, (4) empathisch reageren, (5) verdere informatie geven en uiteindelijk afsluiten en een beslissing nemen (Buckman, 1992).

\section{Voorbereiding van een slechtnieuwsgesprek}

In veel gevallen is het op voorhand duidelijk dat een slechtnieuwsgesprek zal moeten gevoerd worden, bijvoorbeeld als laboresultaten binnenkomen die slecht nieuws betekenen. Op dat moment kan het gesprek voorbereid worden door een juiste setting te creëren (Bateman, 2007). Enerzijds moeten de juiste personen uitgenodigd worden bij dit gesprek: de persoon die de uiteindelijke beslissing zal nemen over het dier en eventuele familieleden of nodige ondersteuning. Het gesprek zelf wordt het best niet over de telefoon gevoerd maar tijdens een consultatie. Voor een slechtnieuwsgesprek moet voldoende tijd worden uitgetrokken en moeten onderbrekingen vermeden worden (bijvoorbeeld GSM afzetten). Een telefonisch gesprek heeft als nadelen dat dit medium zeer beperkt is om een emotioneel zwaarbeladen boodschap over te brengen, dat er onvoldoende emotionele opvang mogelijk is en dat de dierenarts geen zicht heeft op het juiste moment voor de communicatie. De klant is misschien net aan het autorijden, helemaal alleen thuis of op het werk. Anderzijds is het telefonisch uitnodigen van de klant voor het bespreken van de resultaten vaak ook al een duidelijk signaal dat het over slecht nieuws gaat. Het uitnodigen voor een gesprek gebeurt dus het best niet te lang op voorhand om onnodige langdurige stress bij de klant te vermijden. Sommige klanten zullen aandringen op meer informatie aan de telefoon en in bepaalde gevallen kan een slechtnieuwsgesprek ook aan de telefoon gevoerd worden.

Een ander aspect van de voorbereiding is het bepalen van een juist tijdstip. Het brengen van slecht nieuws wordt het beste nooit uitgesteld, ook niet op vraag van de klant of indien het niet het geschikte moment lijkt, bijvoorbeeld bij een landbouwer die net op dat moment ook andere zorgen heeft. Het uitstellen van slecht nieuws kan ervoor zorgen dat de klant het nieuws ondertussen van iemand anders verneemt of het op een andere manier te weten komt, wat uiteraard nefast is voor de vertrouwensband met de dierenarts. Daarnaast zal de klant het slechte nieuws vaak toch al afleiden uit de non-verbale communicatie en het gedrag van de dierenarts (bijvoorbeeld het doorverwijzen van de patiënt). Ook bij een vermoeden van slecht nieuws is het dus beter dit toch uit te spreken; de klant merkt het anders toch op en de fantasie van de klant kan soms erger zijn dan de werkelijkheid. De boodschap "dat het iets ernstigs zou kunnen zijn" zal dan ook vaak geen verrassing zijn maar eerder een bevestiging van het voorgevoel van de klant. Uit de humane geneeskunde blijkt dat patiënten eerlijkheid van de arts sterk appreciëren (Arora, 2003).

Onverwacht slecht nieuws, en zeker onverwachte euthanasie of sterfte, is uiteraard het moeilijkste nieuws om te brengen. De klant heeft zich dan niet kunnen voorbereiden op het slechte nieuws, waardoor ontkenning en woede vaak voorkomende reacties zijn. Indien mogelijk worden de klanten het best toch voorbereid op het slechte nieuws. Dit kan bijvoorbeeld door hen al op te (laten) bellen op het moment dat gestart wordt met de reanimatie van een gehospitaliseerd dier dat plots erg ziek geworden is. Dit laat de klant toe om de ernst van de situatie te vatten en zich al voor te bereiden op het feit dat het dier kan sterven. Zelfs indien slechts tien minuten later gebeld wordt met het nieuws dat het dier overleden is, zal dit veel minder hard aankomen dan hetzelfde nieuws zonder enige verwittiging.

Een laatste onderdeel van de voorbereiding is het inhoudelijke aspect. Voor de consultatie moet alle nodige informatie over het dier gekend en beschikbaar zijn, bijvoorbeeld naam van het dier en de klant, signalement van het dier en alle onderzoeksresultaten. Daarnaast moet alle nodige informatie over de opties voor behandeling voorhanden zijn, zoals kostprijs, neveneffecten en gemiddelde overlevingsduur. Er kan ook al nagedacht worden over de te verwachten reacties en emoties van de klant en mogelijkheden om daar op te reageren. De ruimte waarin de consultatie zal plaatsvinden moet voorzien zijn van voldoende rust en privacy, zonder stoorzenders of onderbrekingen. Idealiter gaan zowel de dierenarts als de klant zitten voor het gesprek, onder een hoek ten opzichte van elkaar en zonder grote 'barrières' tussen beiden in, zoals een tafel of bureau (McMurray en Boysen, 2017). Ook papieren zakdoekjes of een glas water kunnen al voorzien worden.

\section{Eigenaarsperspectief bevragen}

Tijdens een slechtnieuwsgesprek is het van belang om te weten welke hoeveelheid en type informatie de klant nodig heeft, aangezien niet elke klant dezelfde voorkennis heeft of alle informatie wil kennen (Bateman, 2007). Met een open vraag bij het begin van het gesprek wordt duidelijk welke informatie de klant al kent en wat zijn/haar verwachtingen en bezorgdheden zijn. De juiste woordkeuze is hierbij uiteraard van 
belang. Het is ook mogelijk om te beginnen met een korte samenvatting en vervolgens te vragen naar de huidige toestand van het dier. Dit kan echter problemen geven als de klant juist vindt dat het veel beter gaat met het dier. De overgang naar het slechte nieuws wordt dan heel abrupt. Er moeten dus voldoende signalen zijn dat er slecht nieuws zal volgen. Dit kan bijvoorbeeld al door de klant te vragen om te gaan zitten, of door rechtstreeks te vermelden "Ik vrees dat de resultaten van het bloedonderzoek niet zijn waar we op gehoopt hadden." of "Het spijt mij, ik heb slecht nieuws voor u."

In het SPIKES-model wordt vervolgens expliciet gevraagd of verdere informatie mag gegeven worden, bijvoorbeeld "Is het oké als ik verder ga en de laatste resultaten bespreek?" (Baile et al., 2000). Tot slot kan op dat moment of eventueel in een later stadium van het gesprek ook nagevraagd worden of de klant graag alle mogelijke informatie over de ziekte en prognose wil. Uit onderzoek blijkt dat artsen vaak onderschatten hoeveel hun patiënten willen weten (Epstein et al., 2004). De meeste mensen kennen graag alle opties en willen graag mee beslissen. Een minderheid van de patiënten verkiest echter om niet alle informatie te kennen en laat de beslissingen bij voorkeur volledig over aan de arts (Levinson et al., 2005). Uiteraard moet de belangrijkste informatie sowieso meegedeeld worden.

Het bevragen van het eigenaarsperspectief kan soms overgeslagen worden, bijvoorbeeld indien de klant op de hoogte moet gebracht worden van de dood van het dier. In dit geval kan deze stap gebruikt worden na het meedelen van het slechte nieuws, bijvoorbeeld het bevragen van de keuze van de klant met betrekking tot het stoffelijk overschot van het dier.

\section{Slecht nieuws meedelen}

Het slechte nieuws wordt het beste voorafgegaan door een 'warning shot', een signaal aan de klant dat er slecht nieuws aankomt. Voor een groot deel is dit non-verbaal door gezichtsuitdrukking, houding, intonatie of door te gaan zitten voor het gesprek. Het kan ook verbaal, bijvoorbeeld "Ik vrees dat ik slecht nieuws heb" of "Ik vind het jammer maar ik heb geen goed nieuws.".

Vervolgens wordt het slechte nieuws direct, kort en correct meegedeeld, met gebruik van oogcontact en een warme en meelevende toon. Hierbij wordt het beste de naam van het dier gebruikt. Het is van belang om de boodschap zo eerlijk en open mogelijk te brengen, waarbij vage of dubbelzinnige bewoordingen, verkleinwoorden, verbloemen of minimaliseren van de situatie vermeden worden. Bij een oncologisch probleem moet bijvoorbeeld minstens eenmaal expliciet het woord 'kanker' of 'tumor' vermeld worden, en bijvoorbeeld niet "bolletjes in de longen". Vakjargon wordt beperkt en uitgelegd waar het toch nodig is. De boodschap wordt het beste kort gehouden, bij voorkeur in 'chunks' van slechts één à drie zinnen per keer gevolgd door een stilte of vraag of de klant het begrijpt. Regelmatig pauzeren laat ruimte voor de reactie van de klant en geeft de klant tijd om het nieuws te laten doordringen en bezinken.

\section{Emotionele reacties}

Een slechtnieuwsboodschap zal meestal een scala van emoties oproepen. Zeker klanten met een hechte band met hun dier kunnen voor een buitenstaander irrationele reacties vertonen. De band tussen mens en gezelschapsdier ("human - animal bond") wordt door de American Veterinary Medical Association gedefinieerd als "de relatie tussen mens en dier die voordelig en heilzaam is voor de gezondheid en het welzijn van zowel mens als dier" (Knesl et al., 2016). Deze band bestaat uit emotionele, psychologische en fysieke interacties tussen dier en mens. Het erkennen van deze band en de emoties die hieruit volgen zijn dan ook van belang in de dierenarts-klantcommunicatie.

Rouw is de reactie van mensen op een verlies. Primair verlies wordt hierbij gedefinieerd als het sterven van een dier, met rouw omwille van gemis van het dier zelf. Daarnaast zijn er ook andere vormen van verlies die frequent voorkomen in een diergeneeskundige context. Secundair verlies bestaat uit het verlies van contact met het dier en sociaal contact door het dier, bijvoorbeeld gaan wandelen met de hond of contact met dierenarts of hondentrimmer. Verder kan een verlieservaring ook gepaard gaan met blijvende vragen, waarbij de klant onzeker achterblijft, bijvoorbeeld bij een weggelopen dier, diefstal of een onbekende doodsoorzaak. Tot slot kan ook symbolisch verlies optreden, waarbij het dier een symbolische waarde heeft of gelinkt is met eerdere verlieservaringen bij de klant, bijvoorbeeld dier van overleden echtgenoot of dier gelinkt met een bepaalde levensfase die nu definitief afgesloten wordt. Een aantal factoren maken de klant gevoeliger voor verlies, bijvoorbeeld alleen wonen, andere gelijktijdige verlieservaringen, chronische ziekte of depressie bij de klant of traumatisch verlies van het dier zoals bij een ongeluk. Deze factoren zijn vaak niet gekend door de dierenarts en kunnen verklaren waarom sommige klanten veel emotioneler op verlies reageren dan andere.

$\mathrm{Bij}$ het rouwen om een verlieservaring worden traditioneel vaak de vijf verschillende fasen beschreven die gedefinieerd werden door Kübler-Ross: weerstand en ontkenning, protest en woede, onderhandelen en vechten, depressie en machteloosheid en tot slot aanvaarding. De duur en de volgorde van de verschillende fasen kunnen echter sterk individueel verschillen (Wortman en Silver, 1989). Het verlies van een dier kan daarnaast nog een heel scala aan andere emoties teweegbrengen, waaronder ook gevoelens van verlating, verwarring, angst, schuldgevoel, opluchting, etc. Als dierenarts is het mogelijk om klanten te helpen omgaan met rouw door hen deze gevoelens te laten 
Tabel 2. Vijf fasen van rouw volgens Kübler-Ross geïllustreerd met een voorbeeld uit de diergeneeskunde: een kat werd gediagnosticeerd met chronisch nierfalen in IRIS (International Renal Interest Society) stadium IV.

\begin{tabular}{|c|c|}
\hline $\begin{array}{l}\text { Weerstand } \\
\text { Ontkenning }\end{array}$ & "Het kan niet dat mijn kat nierfalen heeft, gisteren was ze nog gewoon aan het eten." \\
\hline $\begin{array}{l}\text { Protest } \\
\text { Woede }\end{array}$ & $\begin{array}{l}\text { "Als u een goede dierenarts zou zijn, dan zou u vinden wat er wel aan de hand is in plaats } \\
\text { van zo snel iets te zeggen!" }\end{array}$ \\
\hline $\begin{array}{l}\text { Onderhandelen } \\
\text { Vechten }\end{array}$ & $\begin{array}{l}\text { "Kunnen we niet behandelen met een speciaal supplement? Ik vond op het internet } \\
\text { iets dat de nierfunctie verbetert." }\end{array}$ \\
\hline $\begin{array}{l}\text { Depressie } \\
\text { Machteloosheid }\end{array}$ & "Ik ga haar zo missen, ik ga nooit een andere kat nemen." \\
\hline $\begin{array}{l}\text { Aanvaarding (meestal pas } \\
\text { na langere tijd) }\end{array}$ & $\begin{array}{l}\text { "Wat kunnen we nu doen om haar leven zo goed mogelijk te houden voor de tijd } \\
\text { die ze nog heeft?" }\end{array}$ \\
\hline
\end{tabular}

uiten en hierop empathisch te reageren (Adams et al., 2000). Indien rouwgevoelens vrijuit kunnen uitgedrukt worden duurt de herstelperiode na een verlies minder lang (Shaw en Lagoni, 2007) (Tabel 2).

\section{Empathisch reageren}

Reageren op emoties na slecht nieuws kan door empathische communicatie, actief luisteren en open vragen, met aandacht voor non-verbale communicatie. Het erkennen en accepteren van alle emoties is een essentieel onderdeel van empathische communicatie (Adams en Kurtz, 2017; McMurray en Boysen, 2017). Empathisch reageren gebeurt voor een groot deel non-verbaal, door een pauze of stilte te laten. Het erkennen en accepteren van emoties kan ook expliciet verbaal door de band tussen de klant en het dier te benadrukken en de emoties te normaliseren en legitimeren, bijvoorbeeld "Ik weet dat Toby heel veel betekent voor $\mathrm{u}$, het is normaal dat dit nieuws erg hard aankomt." Een empathische reactie kan ook bestaan uit het benoemen van de emoties en dit te linken aan de oorzaak ervan, bijvoorbeeld "Ik zie dat u het lastig hebt met het nieuws over Toby's kanker.", "Ik zie dat $\mathrm{u}$ dit nieuws niet verwachtte...", "Hoe is het voor $\mathrm{u}$ dit nieuws nu te horen...?" Een aanraking kan ook onderdeel zijn van een empathische reactie, al zal dit sterk afhangen van de persoonlijke voorkeur en band tussen dierenarts en klant.

Actief luisteren geeft aan dat de dierenarts aandacht heeft voor de emoties en zorgen van de klant. Non-verbaal kan dit door oogcontact, een open houding en non-verbale signalen van aandacht, zoals knikken of neutrale aanmoedigingen, bijvoorbeeld "hmm-hmm". Verbaal kan dit door het checken van de eigen interpretatie van wat de klant wil zeggen, bijvoorbeeld door parafraseren, herhalen of open vragen. Door het inpikken op cues of hints van de klant kan meer te weten gekomen worden over de verwachtingen, emoties en bezorgdheden van de klant. Dit geeft de klant bijvoorbeeld de kans om uit te leggen waar hij of zij het meeste zorgen over heeft. In sommige gevallen zijn de emoties bij de klant na slecht nieuws niet per se door het slechte nieuws zelf veroorzaakt, maar door andere zaken die op dat moment naar boven komen. Door het benoemen van de emoties krijgt de klant de kans om dit te verduidelijken, of om aan te geven dat hij of zij klaar is om verder te gaan met de consultatie.

Een gebrek aan empathie is een vaak voorkomende oorzaak van klachten over dierenartsen (Shaw et al., 2004a), terwijl empathisch reageren geassocieerd is met een hogere tevredenheid bij zowel klant als dierenarts (McArthur en Fitzgerald, 2013; Shaw et al., 2012). Anderzijds worden slechts in een minderheid van de kleinehuisdierenconsultaties empathische uitspraken gedaan (McArthur en Fitzgerald, 2013; Shaw et al., 2004b). Bij het brengen van slecht nieuws zal een dierenarts zelf vaak een aantal defensiemechanismen gebruiken, een zelfbeschermingsreflex voor de confrontatie met emoties. Deze defensiemechanismen bestaan onder andere uit vroegtijdig geruststellen van de klant, humor, afleiding door het onderwerp te veranderen, bagatelliseren van het slechte nieuws of de emoties of enkel aandacht hebben voor de fysieke/ biomedische aspecten. Empathisch reageren is echter een veel effectievere manier om met de emoties van de klant om te gaan.

Soms kan de klant in dit stadium lastige vragen stellen. Een typisch voorbeeld hierbij is "Hoe lang heeft mijn dier nog?" Het meedelen van een exacte prognose is hier gevaarlijk, aangezien dit meestal zeer moeilijk in te schatten is. In veel gevallen is deze vraag ook geen vraag naar concrete cijfers, maar eerder het verwoorden van de emoties die gepaard gaan met het slechte nieuws of een vraag naar "Wat is er te verwachten?" Uitspraken hierover gaan dan ook het beste gepaard met de hoop op 'zo lang mogelijk zo goed mogelijk'.

\section{Plannen}

Het geven van informatie heeft geen zin op het moment dat de klant nog erg emotioneel is en dus niet 
open staat voor nieuwe informatie. Door empathische reacties zakken de emoties zodat de klant terug in het rationele gebied komt waarin informatie kan gegeven worden (Figuur 2). Deze nieuwe informatie kan echter op zijn beurt ook nieuwe emoties oproepen, waarop dan opnieuw empathisch gereageerd moet worden. De klant zal meestal zelf aangeven dat hij/zij klaar is voor nieuwe informatie door een vraag te stellen of oogcontact te maken. Indien mogelijk worden beslissingen niet overhaast genomen en krijgt de klant wat tijd om de verschillende opties te overdenken en eventueel op een vervolgafspraak te bespreken. In spoedgevallen moet uiteraard snel een beslissing genomen worden. Hierbij moet duidelijk aangegeven worden hoeveel tijd de klant hiervoor heeft: is een onmiddellijke beslissing nodig, kan de klant nog overleggen met gezinsleden of kan het dier mogelijk enkele uren gestabiliseerd worden?

Bij het geven van informatie na slecht nieuws zijn dezelfde vaardigheden nodig als bij een andere consultatie (Adams en Kurtz, 2017). Deze vaardigheden zijn nu echter nog belangrijker aangezien de klant in een emotionele toestand meestal niet klaar is voor een grote hoeveelheid informatie. Een eerste stap is het vertrekken vanuit het eigenaarsperspectief, bijvoorbeeld: wat betekent levenskwaliteit van het dier voor de klant? Een tweede techniek is de zogenaamde 'chunk and check'-strategie, waarbij een korte uitleg afgewisseld wordt met regelmatige pauzes en vragen om te controleren of de klant alles begrijpt. Uiteraard wordt de hoeveelheid vaktaal beperkt of wordt deze waar nodig verder uitgelegd. Een derde techniek is het structureren van de informatie. Hierbij wordt eerst aangekondigd welke informatie zal gegeven worden, vervolgens volgt de informatie zelf opgedeeld in overzichtelijke stappen, en tot slot wordt samengevat welke informatie gegeven werd. Een vierde techniek is het markeren van de belangrijkste delen van de uitleg door deze verbaal en non-verbaal te benadrukken en te herhalen. Tot slot kunnen ook hulpmiddelen gebruikt worden, zoals een geschreven samenvatting of een folder met informatie. Het gesprek afsluiten gebeurt door nogmaals samen te vatten welke informatie gegeven is en welke beslissingen genomen zijn.

Zeker na het brengen van slecht nieuws is het uitermate belangrijk om naast empathie ook voldoende ondersteuning aan te bieden (Bateman, 2007). Praktisch kan dit bijvoorbeeld bestaan uit een aanbod om contact op te nemen met familieleden om het slechte nieuws te brengen, het ter beschikking staan van de klant bij vragen of het inplannen van een vervolgafspraak of tijdstip voor een telefonisch gesprek. Afhankelijk van de emoties bij de klant kan het nodig zijn om te controleren of hij/zij in staat is om met de auto naar huis te rijden of hiervoor beter hulp vraagt aan familieleden. De klant kan eventueel ook doorverwezen worden naar (online)-steungroepen of zelfs rouwbegeleiding (Adams et al., 2000).

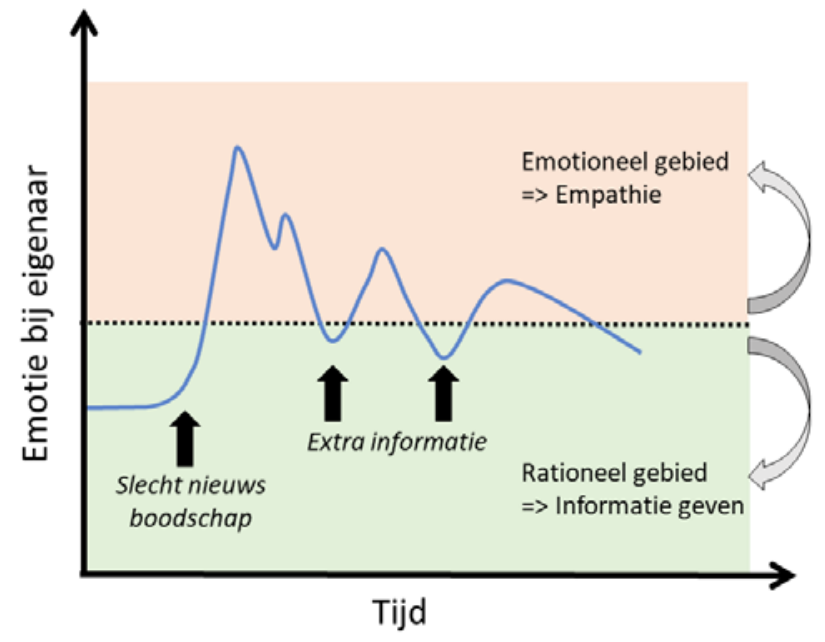

Figuur 2. Emotionele reacties na het brengen van slecht nieuws en aanpak van deze reacties. Na het brengen van slecht nieuws gaat de klant vaak over in een emotionele toestand waarin hij/zij niet open staat voor meer informatie en verdere planning. Empathisch reageren kan ervoor zorgen dat de emoties beheersbaar worden en de klant terug in het rationele gebied terechtkomt, waarbij informatie kan gegeven worden. Deze informatie kan echter ook nieuwe emoties uitlokken. (Uit: Deveugele en van Weel-Baumgarten, 2014).

\section{CONCLUSIE}

Slecht nieuws komt frequent voor in de diergeneeskundige praktijk. De verschillende modellen voor het slechtnieuwsgesprek uit de humane geneeskunde kunnen ook toegepast worden binnen de diergeneeskunde. Een goede aanpak van het slechtnieuwsgesprek kan bij zowel dierenarts als klant de stress verminderen en tevredenheid verhogen. Bovendien laat het toe om de nodige informatie correct over te brengen met aandacht voor eventuele emotionele reacties.

\section{REFERENTIES}

Adams, C., Kurtz, S. (2017). Skills for Communicating in Veterinary Medicine. Otmoor Publishing Ltd., Oxford.

Adams, C.L., Bonnett, B.N., Meek, A.H. (2000). Predictors of owner response to companion animal death in 177 clients from 14 practices in Ontario. Journal of the American Veterinary Medical Association 217, 1303-1309.

Arora, N.K. (2003). Interacting with cancer patients: the significance of physicians' communication behavior. Social Science \& Medicine 57, 791-806.

Baile, W.F., Buckman, R., Lenzi, R., Glober, G., Beale, E.A., Kudelka, A.P. (2000). SPIKES-A six-step protocol for delivering bad news: application to the patient with cancer. Oncologist 5, 302-311.

Bateman, S.W. (2007). Communication in the veterinary emergency setting. Veterinary Clinics of North America Small Animal Practice 37, 109-121. 
Buckman, R. (1984). Breaking bad news: why is it still so difficult? British Medical Journal 288, 1597-1599.

Buckman, R. (1992). How to Break Bad News: A Guide for Health Care Professionals. University of Toronto Press, Scholarly Publishing Division, Toronto.

De Lepeleire, J., Keirse, M. (2011). Aan weerszijde van de stethoscoop. Over kwaliteit van zorg en communicatie. Acco, Leuven.

Deveugele, M., van Weel-Baumgarten, E. (2014). Slechtnieuwsboodschappen. Leerboek voor Huisartsgeneeskunde. De Tijdstroom uitgeverij, Utrecht, p. 117-126.

Epstein, R.M., Alper, B.S., Quill, T.E. (2004). Communicating evidence for participatory decision making. Journal of the American Medical Association 291, 2359-2366.

Fallowfield, L., Jenkins, V. (2004). Communicating sad, bad, and difficult news in medicine. Lancet 363, 312-319.

Frankel, R.M. (2006). Pets, vets, and frets: What relationship-centered care research has to offer veterinary medicine. Journal of Veterinary Medical Education 33, 20-27.

Hewson, C. (2015). Grief for pets. Part 3: Supporting clients. Veterinary Nursing Journal 30, 26-30.

Knesl, O., Hart, B.L., Fine, A.H., Cooper, L. (2016). Opportunities for incorporating the human-animal bond in companion animal practice. Journal of the American Veterinary Medical Association 249, 42-44.

Levinson, W., Kao, A., Kuby, A., Thisted, R.A. (2005). Not all patients want to participate in decision making - A national study of public preferences. Journal of General Internal Medicine 20, 531-535.

McArthur, M.L., Fitzgerald, J.R. (2013). Companion animal veterinarians' use of clinical communication skills. Australian Veterinary Journal 91, 374-380.

McMurray, J., Boysen, S. (2017). Communicating empathy in veterinary practice. Veterinary Ireland Journal 7, 199-205.

Nickels, B.M., Feeley, T.H. (2018). Breaking bad news in veterinary medicine. Health Communication 33, 11051113.

Ptacek, J.T., Leonard, K., McKee, T.L. (2004). “I've got some bad news ...": Veterinarians' recollections of communicating bad news to clients. Journal of Applied Social Psychology 34, 366-390.

Rabow, M.W., McPhee, S.J. (1999). Beyond breaking bad news: how to help patients who suffer. Western Journal of Medicine 171, 260-263.

Roberts, C.S., Cox, C.E., Reintgen, D.S., Baile, W.F., Gibertini, M. (1994). Influence of physician communica- tion on newly-diagnosed breast patients psychologic adjustment and decision-making. Cancer 74, 336-341.

Rosenbaum, M.E., Ferguson, K.J., Lobas, J.G. (2004). Teaching medical students and residents skills for delivering bad news: A review of strategies. Academic Medicine 79, 107-117.

Shaw, J.R., Adams, C.L., Bonnett, B.N. (2004a). What can veterinarians learn from studies of physician-patient communication about veterinarian-client-patient communication? Journal of the American Veterinary Medical Association 224, 676-684.

Shaw, J.R., Adams, C.L., Bonnett, B.N., Larson, S., Roter, D.L. (2004b). Use of the roter interaction analysis system to analyze veterinarian-client-patient communication in companion animal practice. Journal of the American Veterinary Medical Association 225, 222-229.

Shaw, J.R., Adams, C.L., Bonnett, B.N., Larson, S., Roter, D.L. (2012). Veterinarian satisfaction with companion animal visits. Journal of the American Veterinary Medical Association 240, 832-841.

Shaw, J.R., Lagoni, L. (2007). End-of-life communication in veterinary medicine: delivering bad news and euthanasia decision making. Veterinary Clinics of North America Small Animal Practice 37, 95-108.

Vala, H., Esteves, F., Mega, A., Santos, C., Cruz, R., Nóbrega, C., Mesquita, J.R. (2016). Adaptation of the ABCDE model from human medicine to communicate bad news to the owner of the oncologic patient in Veterinary Medicine. Millennium 2, 27-35.

Vandekieft, G.K. (2001). Breaking bad news. American Family Physician 64, 1975-1978.

Villagran, M., Goldsmith, J., Wittenberg-Lyles, E., Baldwin, P. (2010). Creating COMFORT: A communicationbased model for breaking bad news. Communication Education 59, 220-234.

Williams, S., Mills, J.N. (2000). Understanding and responding to grief in companion animal practice. Australian Veterinary Practitioner 30, 55-62.

Wittenberg, E., Reb, A., Kanter, E. (2018). Communicating with patients and families around difficult topics in cancer care using the COMFORT communication curriculum. Seminars in Oncology Nursing 34, 264-273.

Wortman, C.B., Silver, R.C. (1989). The myths of coping with loss. Journal of Consulting and Clinical Psychology 57, 349-357. 